\title{
TraumaTutor: Perceptions of a Smartphone Application as a Learning Resource for Trauma Management
}

\author{
James Wigley ${ }^{1}$ and Saran Shantikumar ${ }^{2}$ \\ ${ }^{1}$ University Hospital Southampton, Tremona Road, Southampton SO16 6NY, UK \\ ${ }^{2}$ Bristol Heart Institute, Upper Maudlin Street, Bristol BS2 8HW, UK \\ Correspondence should be addressed to James Wigley; james.wigley@gmail.com
}

Received 30 April 2013; Accepted 23 June 2013

Academic Editor: Friedrich Paulsen

Copyright (c) 2013 J. Wigley and S. Shantikumar. This is an open access article distributed under the Creative Commons Attribution License, which permits unrestricted use, distribution, and reproduction in any medium, provided the original work is properly cited.

\begin{abstract}
Aim. We investigated perceptions of a new smartphone application (app) as a learning resource. Methods. We developed TraumaTutor, an iPhone app consisting of 150 questions and explanatory answers on trauma management. This was used by 20 hospital staff that either had a special interest in managing trauma or who were studying for relevant exams, such as ATLS. A subsequent questionnaire assessed users' experience of smartphone applications and their perceptions of TraumaTutor. Results. Of those surveyed, $85 \%$ had a device capable of running app software, and $94 \%$ of them had used apps for medical education. Specific to TraumaTutor, $85 \%$ agreed that it was pitched at the right level, $95 \%$ felt that the explanations improved understanding of trauma management, and $100 \%$ found the app easy to use. In fact, on open questioning, the clear user interface and the quality of the educational material were seen as the major advantages of TraumaTutor, and 85\% agreed that the app would be a useful learning resource. Conclusions. Smartphone applications are considered a valuable educational adjunct and are commonly used by our target audience. TraumaTutor shows overwhelming promise as a learning supplement due to its immediacy, accessibility, and relevance to those preparing for courses and managing trauma.
\end{abstract}

\section{Introduction}

Since the smartphone was unveiled in $2000[1,2]$, and in particular the iPhone in 2007 , its uses and adaptability have been an unbridled success story with over 40 billion applications (apps) being downloaded worldwide by 2013 [3]. Educational apps are becoming increasingly commonplace with more people turning to the online marketplace to gather and consolidate information.

We developed TraumaTutor, an app created with the intention of improving the understanding of trauma in the acute setting amongst hospital staff. The program consists of 150 single best answer questions and detailed explanatory answers of trauma management. Based on the widely adopted syllabus of the Advanced Trauma Life Support course, TraumaTutor encompasses the fundamental principles of trauma management, with chapters dedicated to individual aspects of the primary survey as well as the specialist management of trauma in children, pregnancy, and the elderly. We investigated the perceptions of TraumaTutor as a learning resource amongst its intended target audience.

\section{Methods}

Twenty hospital staff of varying grades who had a special interest in trauma (emergency department specialist nurses, junior doctors, and consultants in emergency medicine and surgery) were asked to use TraumaTutor over a five-minute period before completing a questionnaire anonymously. No additional guidance was given on how to use the program after entering the home screen. Likert-style questions evaluated respondents' current use of similar products, the app's usability, the depth of information given, and its ability to provide explanations at an appropriate level. Respondents also had the opportunity to provide feedback on what was good about the app and what could be improved.

\section{Results}

Table 1 displays the first six questions of the questionnaire (Likert-type statements) along with their responses. Overall, 
TABLE 1: Summary of the responses to the Likert stems of the questionnaire.

\begin{tabular}{|c|c|c|c|}
\hline Statement & $\begin{array}{c}\text { "Strongly } \\
\text { disagree"/“disagree"/“neither } \\
\text { agree nor disagree" }\end{array}$ & "Agree" & "Strongly agree" \\
\hline Apps are a useful resource to supplement learning & $10 \%$ & $55 \%$ & $35 \%$ \\
\hline Having an educational app such as this would allow me to study "on the go" & $25 \%$ & $40 \%$ & $35 \%$ \\
\hline $\begin{array}{l}\text { The questions are pitched at the right level for healthcare staff participating } \\
\text { in trauma courses, such as ATLS }\end{array}$ & $15 \%$ & $45 \%$ & $40 \%$ \\
\hline $\begin{array}{l}\text { The detail of the answers improves my understanding of the management } \\
\text { of trauma }\end{array}$ & $5 \%$ & $25 \%$ & $70 \%$ \\
\hline I found the layout of the app easy to use and understand & $0 \%$ & $25 \%$ & $75 \%$ \\
\hline I find this a useful resource to supplement my learning & $15 \%$ & $25 \%$ & $60 \%$ \\
\hline
\end{tabular}

hospital staff thought that the app would be useful as an educational resource enabling them to develop their knowledge of trauma management.

Of those surveyed, $85 \%$ had a device capable of running app software, and $94 \%$ of these had used apps for medical education previously. Specific to TraumaTutor, 85\% agreed that it was pitched at the right level, 95\% felt that the explanations improved understanding, and $100 \%$ found the app easy to use. In fact, on open questioning, the clear user interface and the quality of the educational material were seen as the major advantages, and $85 \%$ agreed that the app would be a useful learning resource.

Users were also asked to list which specific apps they had used for medical education. A total of 24 medical apps were listed, ranging from those used as reference tools such as the "British National Formulary" to those utilised for learning "on the go" such as "Anatomy flash cards." Of the $85 \%$ of people who owned devices capable of running app software, the vast majority had iPhones or iPads. On open questioning, the responses praised the "attractive" and "clear" format allowing users to "work through in sections." Furthermore, the "detail of explanations" aiding "supplemental learning" was also acknowledged. On asking about what could be improved, one user (a consultant in emergency medicine) called for the app to be more UK centric and two others suggested listing alternative resources to supplement learning.

\section{Discussion}

Over the past few years, medical education has evolved rapidly with a shift from traditional didactic lectures to more interactive and diverse styles of teaching. Students have never before had access to so much information combined with the flexibility to learn in accordance with their own educational needs. In this study, we evaluate whether mobile apps are recognized as a genuine educational resource.

In summary, hospital staff who had an interest in trauma management were asked to complete a questionnaire after using a new smartphone app. Our results demonstrate that the use of such apps amongst staff is widespread. Specifically regarding TraumaTutor, users were impressed by its usability and its efficacy in delivering information about trauma management.
There are limitations associated with the study. Although the questionnaires were completed anonymously, users may not have scored the answers so favourably if they were completed in privacy. The low number of participants in this survey may also inhibit result reliability. However, the authors believe that the diversity of persons questioned was representative of the target audience. Whilst the survey demonstrates the app's appeal as an education tool, we are unable to suggest whether its use would be followed by improvements in clinical management and patient outcomes.

Technology-assisted learning has always been exploited, with the use of cassette tapes [4], computer-based packages [5], web-based learning tools [6], and podcasts [7]. Now, there is a growing wealth of research to support the use of smartphones in medical education. Even in remote destinations such as Botswana, evidence has shown smartphones to be of benefit for accessing point-of-care medical information at the bedside and in engaging users' self-directed learning at home [8]. Smartphones use is common amongst both clinicians and medical students. A US survey of 300 physicians of all grades found that $85 \%$ had a smartphone-a proportion similar to ours-and 50\% used apps for medical education [9]. A similar survey of UK medical students described that over $75 \%$ owned a smartphone and that most had one to five apps of relevance to medical education [10]. Smartphone apps are therefore clearly an educational target. Indeed, a recent study reported improvements in the management of emergencies following the use of a smartphone app [11]: use of the app "iResus" was shown to significantly raise the scores of ALS-trained doctors when subjected to a simulated medical emergency compared with those who had no such experience with the app [11].

\section{Conclusions}

Our study aimed to evaluate the perceptions of a new smartphone app. We conclude that apps are considered a valuable educational adjunct and are commonly used by our target audience. Specifically, TraumaTutor shows overwhelming promise as a learning supplement due to its immediacy, accessibility, and relevance to those preparing for courses and managing trauma. 


\section{References}

[1] Apple, “App Store Tops 40 Billion Downloads with Almost Half in 2012," 2013, http://www.apple.com/uk/pr/library/2013/01/07App-Store-Tops-40-Billion-Downloads-with-Almost-Half-in2012.html.

[2] “Geek.com PDA Review: Ericsson R380 Smartphone," 2013, http://www.geek.com/hwswrev/pda/ericr380/ .

[3] "Symbian Blog. Symbian Device-The OS Evolution. Independent Symbian Blog," 2013, http://my-nokia-cell.blogspot.com/2011/ 08/symbian-belle-next-evolution-of-os.html.

[4] M. A. Mir, R. J. Marshall, and R. W. Evans, “Teaching medical history-taking: a comparison between the use of audio- and videotapes," Medical Education, vol. 20, no. 2, pp. 102-108, 1986.

[5] P. Devitt, S. Worthley, E. Palmer, and D. Cehic, "Evaluation of a computer based package on electrocardiography," Australian and New Zealand Journal of Medicine, vol. 28, no. 4, pp. 432-435, 1998.

[6] E. B. Allen, R. T. Walls, and F. D. Reilly, "Effects of interactive instructional techniques in a web-based peripheral nervous system component for human anatomy," Medical Teacher, vol. 30, no. 1, pp. 40-47, 2008.

[7] S. Shantikumar, "From lecture theatre to portable media: students' perceptions of an enhanced podcast for revision," Medical Teacher, vol. 31, no. 6, pp. 535-538, 2009.

[8] A. Y. Chang, S. Ghose, R. Littman-Quinn et al., "Use of mobile learning by resident physicians in Botswana," Telemedicine and E-Health, vol. 18, no. 1, pp. 11-13, 2012.

[9] O. I. Franko and T. F. Tirrell, "Smartphone app use among medical providers in ACGME training programs," Journal of Medical Systems, vol. 36, no. 5, pp. 3135-3139, 2012.

[10] K. F. B. Payne, H. Wharrad, and K. Watts, "Smartphone and medical related App use among medical students and junior doctors in the United Kingdom (UK): a regional survey, Bmc Medical Informatics and Decision Making, vol. 12, p. 121, 2012.

[11] D. Low, N. Clark, J. Soar et al., "A randomised control trial to determine if use of the iResus $\odot$ application on a smart phone improves the performance of an advanced life support provider in a simulated medical emergency," Anaesthesia, vol. 66, no. 4, pp. 255-262, 2011. 

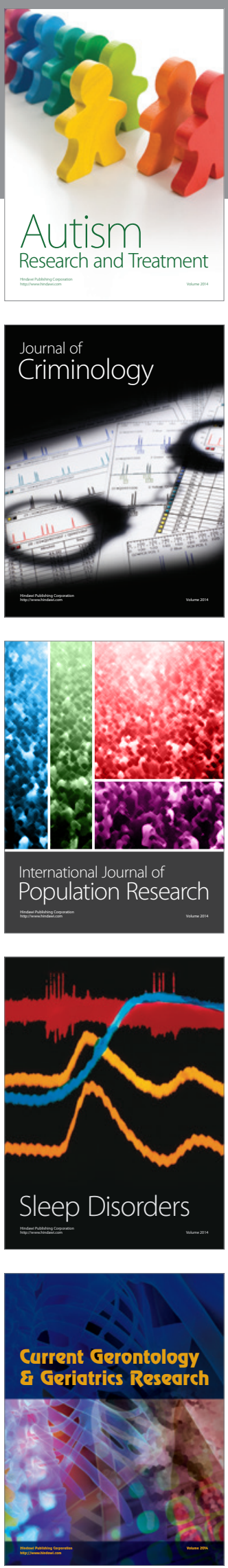
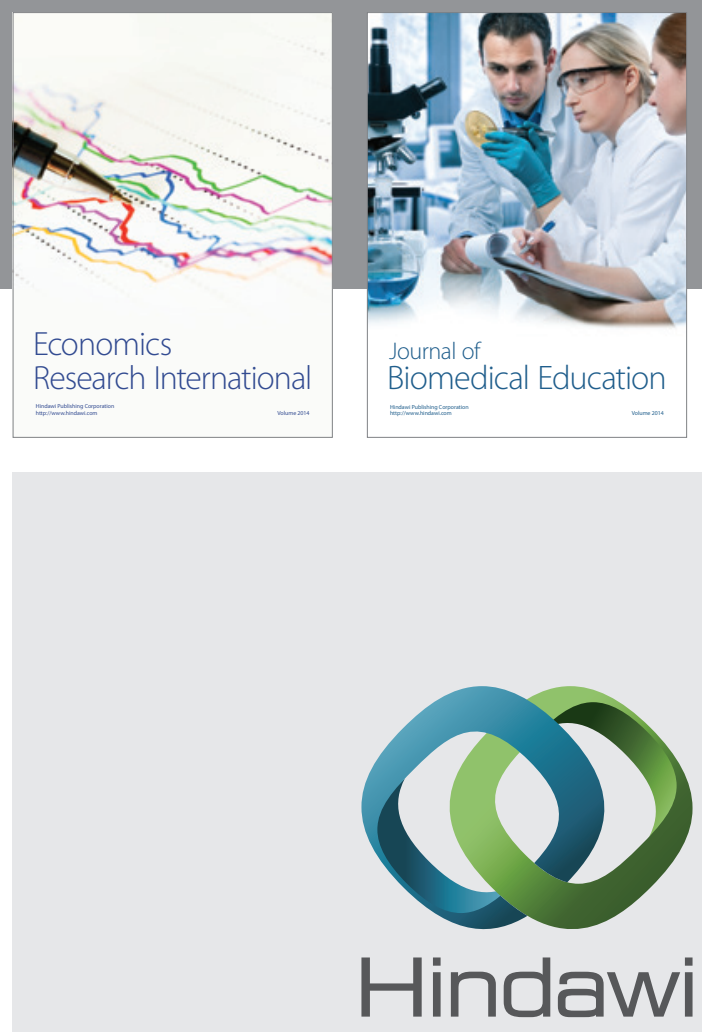

Submit your manuscripts at

http://www.hindawi.com
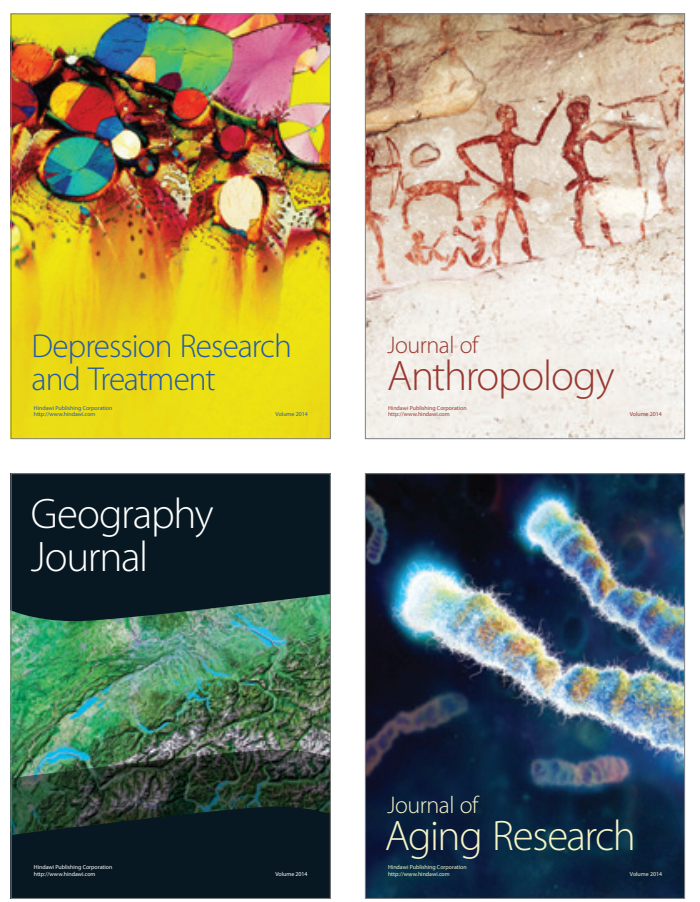
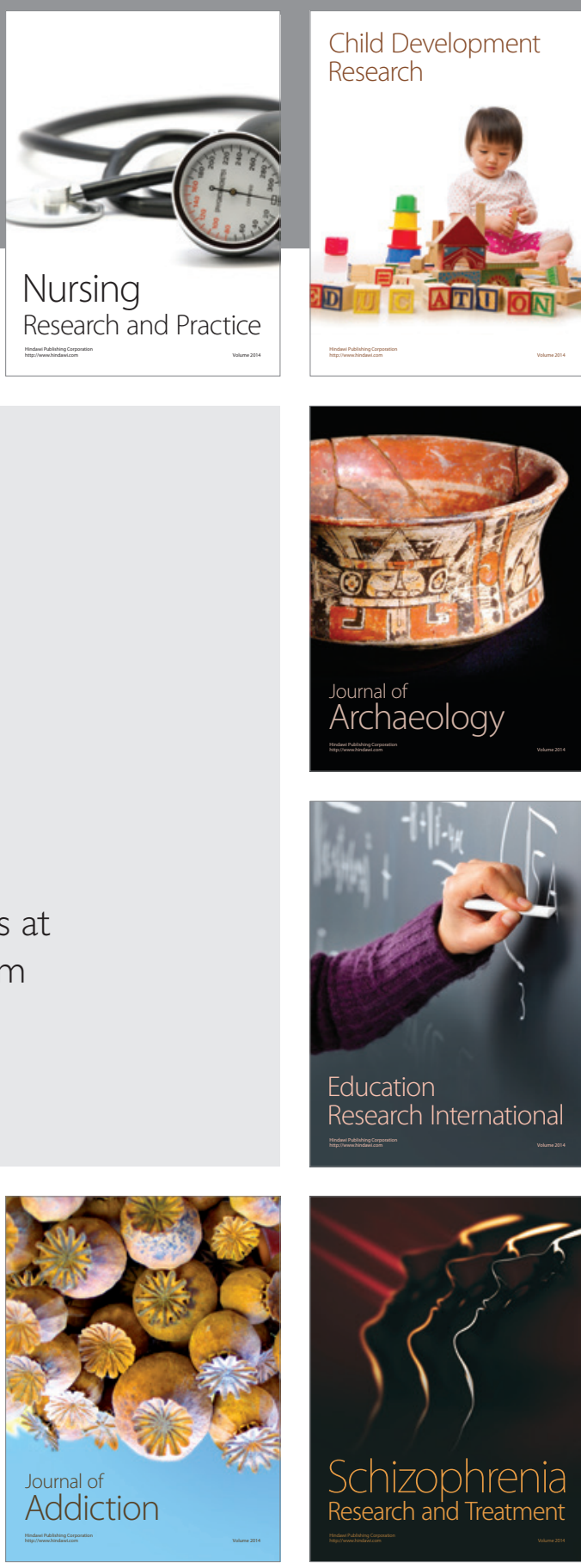

(D)
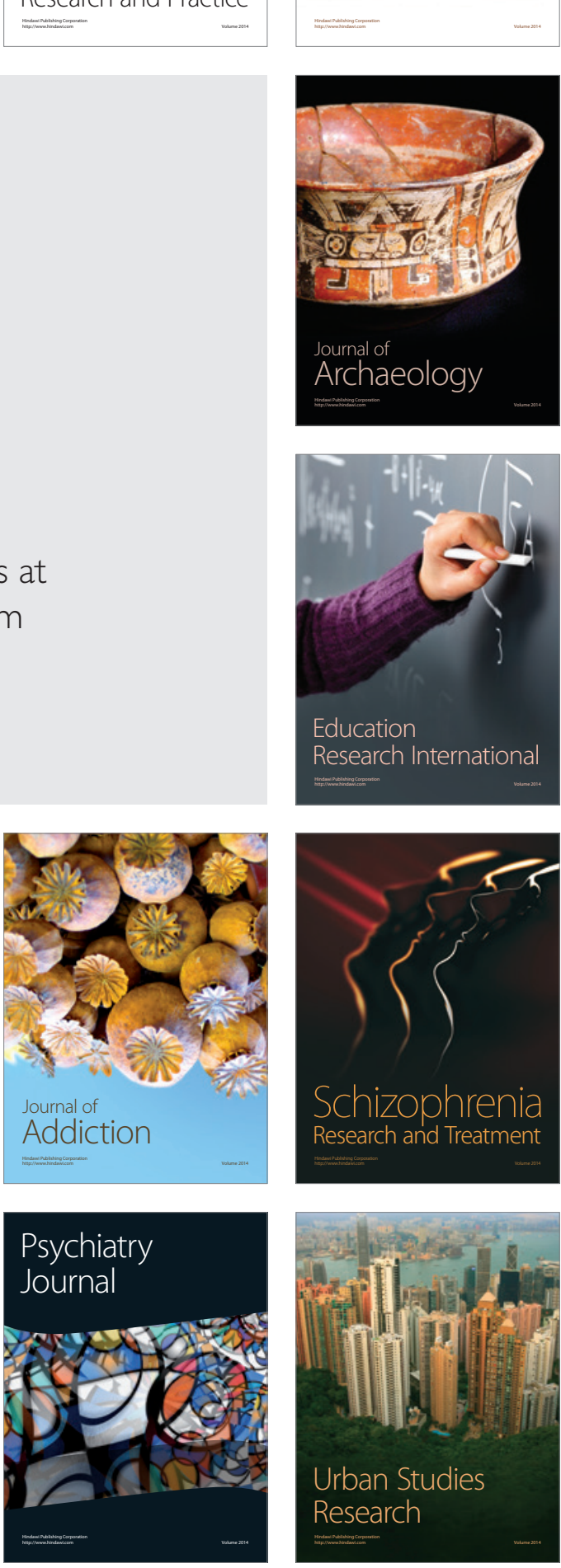